Pesq. Vet. Bras. 37(12):1791-1498, dezembro 2017 DOI: $10.1590 / \mathrm{S} 0100-736 \mathrm{X} 2017001200021$

\title{
Aspecto morfológico da interface entre o compósito, constituído de quitosana e polimetilmetacrilato, e a falha óssea de tíbia de coelhos ${ }^{1}$
}

\author{
Gabriela S. Kuhl², Eliana C.S. Rigo ${ }^{3}$, Luci C.O. Vercik ${ }^{3}$, Renata G.S. Dória², Marcelo \\ D. Santos ${ }^{4}$, Maria C.F.N.S. Hage², Carlos E. Ambrósioº e Silvio H. Freitas ${ }^{2,4 *}$
}

\begin{abstract}
Kuhl G.S., Rigo E.C.S., Vercik L.C.O., Dória R.G.S., Santos M.D., Hage M.C.F.N.S., Ambrósio C.E. \& Freitas S.H. 2017. [Morphological aspect of the interface between the composite, made of chitosan and polymethylmethacrylate, and bone failure of the rabbit tibia.] Aspecto morfológico da interface entre o compósito, constituído de quitosana e polimetilmetacrilato, e a falha óssea de tíbia de coelhos. Pesquisa Veterinária Brasileira 37(12):1791-1498. Departamento de Medicina Veterinária, Faculdade de Zootecnia e Engenharia de Alimentos, Universidade de São Paulo, Rua Duque de Caxias Norte 225, Jardim Elite, Pirassununga, SP 13635-900, Brazil. E-mail: silviohfreitas@gmail.com

Orthopedic diseases with bone loss are challenging in both veterinary and human medicine. The aim of this investigation was to analyze and compare the reactions at the interface between the composite, made of chitosan and polymethylmethacrylate, and the bone defect (receptor site) of the rabbits tibia through radiological and microscopic techniques and by scanning electron microscopy, in different periods. Twelve adult New Zealand rabbits were divided into four experimental groups (E1, $n=3 ; E 2, n=3 ; E 3, n=3$ and $E 4, n=3$ ), which had the right tibial bone defects filled with the composite, and evaluated in the immediate postoperative, 30, 60, 90 and 120 days. Composite implanted in the tibia of rabbits, only two remained in their beds receivers, while the remaining were encapsulated in the subcutaneous tissue. Spheres of chitosan present in the biomaterial that has been deployed and were in direct contact with the bone defect, were preserved, however, were not integrated into the bone tissue. Therefore, to understand the behavior of chitosan as a bone substitute, further research is needed.
\end{abstract}

INDEX TERMS: Chitosan, polymethylmethacrylate, bone failure, rabbit, tibia, osteointegration.

RESUMO.- As afecções ortopédicas com perda de tecido ósseo são um desafio não só na medicina veterinária mas também na medicina humana. Analisou a interface entre compósito, constituído de esferas de quitosana e polimetilmetacrilato em falha óssea (leito receptor) de tíbia de coelhos, por meio de técnica radiológica, avaliação macroscópica e pela microscopia eletrônica de varredura, em dife-

\footnotetext{
${ }^{1}$ Recebido em 11 de outubro de 2016.

Aceito para publicação em 20 de abril de 2017.

${ }^{2}$ Departamento de Medicina Veterinária (ZMV), Faculdade de Zootecnia e Engenharia de Alimentos (FZEA), Universidade de São Paulo (USP), Rua Duque de Caxias Norte 225, Jardim Elite, Pirassununga, SP 13635-900, Brasil.*Autor para correspondência: silviohfreitas@gmail.com

${ }^{3}$ Departamento de Ciências Básicas (ZAB), FZEA-USP, Rua Duque de Caxias Norte 225, Jardim Elite, Pirassununga, SP 13635-900.

${ }^{4}$ Faculdade de Medicina Veterinária (FMV), Universidade de Cuiabá (Unic), Rua Itália s/n, Jardim Europa, Cuiabá, MT 78065-420, Brasil.
}

rentes tempos. Foram utilizados 12 coelhos adultos da raça Nova Zelândia, divididos em quatro Grupos Experimentais (E1, $n=3 ; E 2, n=3 ; E 3, n=3$ e $E 4, n=3$ ), que tiveram as falhas ósseas das tibiais direitas preenchidas com compósito, e avaliadas no pós-operatório imediato, aos 30,60 e 90 e 120 dias. Dos compósitos implantados nas tíbias de coelhos, apenas dois permaneceram em seus leitos receptores, enquanto que os demais se encontravam encapsulados no tecido subcutâneo. As esferas de quitosana, presentes nas superfícies dos biomateriais implantados, que mantiveram contato direto com o leito receptor de tíbias de coelhos apresentavam-se preservadas e não integraram ao tecido ósseo. Diante disso, para melhor compreensão do comportamento da quitosana como substituto ósseo, novas pesquisas serão necessárias.

TERMOS DE INDEXAÇ̃̃O: Quitosana, polimetilmetacrilato, falha óssea, tíbia, coelhos, osteointegração. 


\section{INTRODUÇÃO}

As afecções ortopédicas com perda de tecido ósseo são um desafio não só na medicina humana mas também na medicina veterinária. Por isso, é frequente ortopedistas se depararem com fraturas cominutivas irredutíveis de ossos longos, neoplasias ósseas ou não-uniões de fraturas, que necessitam de procedimento cirúrgico reparador. Uma das principais opções para o tratamento dessas lesões é a substituição de um segmento ou o preenchimento de falha óssea, com o uso de biomateriais natural ou sintético (Ranzani et al. 1996, Rezende et al. 1998, Alievi et al. 2007, Rocha et al. 2011, Burger et al. 2013, Freitas et al. 2013a). A opção mais viável para reparar falhas ósseas é com o uso auto-enxerto ósseo, visto que acelera a cicatrização óssea e causa mínima reação local. Porém, esse procedimento aumenta a morbidade, a dor, os tempos cirúrgico e anestésico e provoca danos aos tecidos normais. Além disso, não fornece volume suficiente para reparar grandes defeitos ósseos (Friedlaender 1982, Melo et al. 1998, Alievi et al. 2007, Freitas et al. 2014).

Atualmente, vários biomateriais naturais vêm sendo pesquisados para uso na reparação de falhas ósseas de pacientes com afecções ortopédicas. Eles podem ser obtidos a partir de animais da mesma espécie, ou seja, biomaterial alógeno, ou de espécie diferente, isto é, biomaterial heterógeno. Apesar de serem biologicamente inferiores ao biomaterial autógeno, os heterógenos estão sendo bastante utilizados na ortopedia reparadora, com resultados satisfatórios (Lane \& Sandhu 1987, Dasso et al. 1998, Melo et al. 1998, Moraes et al. 2004, Alievi et al. 2007, Milori et al. 2013). Além desses, outros biomateriais naturais como hidroxiapatita e quitosana são empregadas em procedimentos ortopédicos que necessitam de reparo de tecido ósseo (Tadjoedin et al. 2003, Carneiro et al. 2005). As falhas ósseas também podem ser completa e eficientemente preenchidas por biomateriais sintéticos, como cimento de fosfato de cálcio, hidroxiapatita sintética, polimetilmetacrilato, biovidros, entre outros (Kawano et al. 1998, Rezende et al. 1998, Weinfeld et al. 1999, Rahal et al. 2000, Braz et al. 2003, Fernandes et al. 2014, Alves et al. 2010, Freitas et al. 2012, Moreira et al. 2014).

A quitina é originária de carapaças de crustáceos, e também pode ser encontrada em insetos, moluscos e na parede celular de fungos. A quitosana é um biomaterial natural biocompatível e biodegradável constituído de polissacarídeo que tem origem partir da reação de desacetilação parcial de quitina, por tratamento alcalino. Ela pode ser apresentada na forma de gel, pasta, membranas e em pó, com diferentes tipos de granulações (Gerentes 2002, Chen et al. 2005, Spin-Neto et al. 2008, Mendes et al. 2011). Por interagir com o sistema biológico, em especial com a matriz extracelular, atualmente, a quitosana é utilizada na área da engenharia tecidual, para uso na reparação de lesão cutânea, defeito osso e erosão cartilaginosa (Khor \& Lim 2013, Pires et al. 2015).

O polimetilmetacrilato é um biomaterial sintético que possui propriedades biotolerantes, osteocondutoras, além de ser facilmente moldado para obtenção de uma forma mais adequada ao leito receptor. Atualmente, ele é utilizado no reparo de falhas ósseas extensas, tanto na medicina humana, quanto na medicina veterinária (Bauer \& Muschler 2000, Yacubian-Fernandes et al. 2004, Raposo-do-Amaral et al. 2010).

Os biomateriais, tanto naturais quanto sintéticos, de forma geral, devem possuir características que promovam a osteoindução, pela formação de osso a partir de células osteoprogenitoras, oriundas das células mesenquimatosas primitivas sob a influência de um ou mais fatores indutores da matriz óssea; a osteocondução, que se caracteriza pelo crescimento ósseo por meio de aposição de tecido ósseo subjacente na presença de osso ou células mesenquimatosas indiferenciadas, além de serem biocompatíveis, não carcinogênicos, atóxicos, não antigênicos e não promover processos inflamatórios (Alexander 1987, Akamoto \& Trento 2002, Freitas et al. 2008).

O diagnóstico imaginológico, através de avaliação radiológica, permite avaliar o comportamento de biomateriais em procedimentos ortopédicos reconstrutivos. Por meio dela, é possível localizar a posição do biomaterial no leito receptor, a remodelação óssea e, também, quantificar as reações locais. Por isso, nos procedimentos cirúrgicos ortopédicos de rotina e experimentais que necessitam de acompanhamento, o seu uso torna-se imprescindível, não só na medicina humana, como também na medicina veterinária (Freitas et al. 2013b, Moreira et al. 2014).

Através da técnica de microscopia eletrônica de varredura (MEV), as estruturas presentes na interface biomaterial-leito receptor podem ser analisadas em alta resolução, o que proporciona maior compreensão dos fenómenos locais. Dessa forma, a investigação sobre o comportamento biológico local do biomaterial, permite estabelecer a distinção entre o seu contato físico e a adesão química com o leito receptor. Com isso, a MEV torna-se um método auxiliar valioso no estudo das estruturas presentes na interface entre o biomaterial-leito receptor em tíbia de coelhos (Mayer et al. 1998, Gartner \& Hiatt 1999, Saboia et al. 2000, Timm 2005, Costa et al. 2015).

Uma opção de substituto ósseo para reparar grandes falhas ósseas seria uma associação de biomateriais naturais e sintéticos que apresentassem propriedades osteogênicas, osteoindutora e osteocondutora, que proporcionassem sustentação mecânica, de fácil aquisição, baixo custo, que não necessitassem de material especializado para preservação, e que preenchessem completamente o defeito ósseo, eliminando problemas inerentes ao biomaterial autógeno (Friedlaender 1982, Sinibaldi 1989, Melo et al. 1998, Alievi et al. 2007, Freitas et al. 2012). Dessa forma, o objetivo deste trabalho foi avaliar a interação da superfície de contato, isto é, interface, entre o compósito constituído de esferas de quitosana e polimetilmetacrilato em falha óssea de tíbia de coelhos.

\section{MATRIAL E MÉTODOS}

O projeto foi aprovado pela Comissão de Ética no uso de animais, da Faculdade de Medicina Veterinária da Universidade de Cuiabá (FMV-UNIC), sob o número de protocolo 2964/2013.

As esferas de quitosana com diâmetro variando de 1 a 1,1 mm (Fig.1A), obtidas pela técnica de gelificação ionotrópica em tri- 


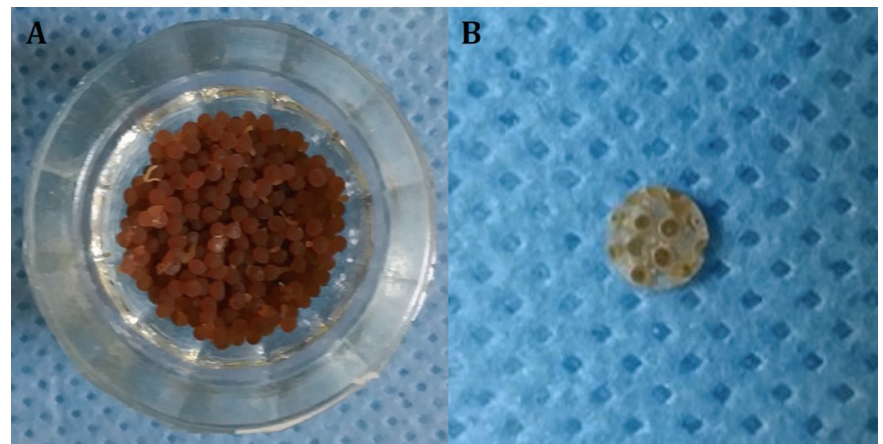

Fig.1. (A) Esferas de quitosana obtidas pela técnica de gelificação ionotrópica em tripolifosfato de sódio (TTP). (B) Compósito constituído de quitosana e polimetilmetacrilato.

polifosfato de sódio (TTP), (Mendes et al. 2011) foram misturados ao polímero (pó) em um recipiente, na mesma proporção, e adicionado o monômero (líquido) polimetilmetacrilato, até atingir a consistência pastosa, que foi depositada sobre uma forma $(4,0 \mathrm{~cm}$ de comprimento x 2,0 cm de largura x $2,0 \mathrm{~mm}$ de espessura). Após a completa polimerização, isto é, a cura, o bloco foi lixado com o uso de lixa d'água ( $\mathrm{n}-400$ ), acoplada em uma politriz/lixadeira metalográfica (PL02E/300), em água corrente, até atingir espessura de $1,0 \mathrm{~mm}$. Com o uso de uma broca trefina (broca copo) de 6,0 mm de diâmetro interno, acoplada à furadeira de baixa rotação presa em uma bancada, foram removidos discos (compósitos) de $6 \mathrm{~mm}$ de diâmetro (Fig.1B), que, para uso, foram acondicionados em grau cirúrgico e esterilizados em autoclave a $121^{\circ} \mathrm{C} / 15 \mathrm{~min}$.

Como controle do experimento, utilizou-se o polimetilmetacrilato presente nos compósitos, que mesmo sendo biocompatível e biotolerável, não é integrado ao tecido ósseo.

Foram utilizados doze coelhos, da ordem Lagomorpha, gênero Oryctolagus, espécie Oryctolagus cuniculus, raça Nova Zelândia, variedade branco, machos e fêmeas, com três meses de idade, pesando entre 3 e 4 kg, divididos em quatro Grupos Experimentais: E1 (30 dias, $\mathrm{n}=3$ ), E2 (60 dias, $\mathrm{n}=3$ ), $\mathrm{E} 3$ (90 dias, $\mathrm{n}=3$ ) e $\mathrm{E} 4$ (120 dias, $\mathrm{n}=3$ ).

Após tricotomia das regiões proximais mediais das tíbias direitas, os coelhos foram anestesiados com uma associação de acepromazina $(0,1 \mathrm{mg} / \mathrm{kg})$ e tiletamina/zolazepam $(20 \mathrm{mg} / \mathrm{kg})$, pela via intramuscular, seguido de bloqueio anestésico com lidocaína, sem vasoconstrictor, sobre o local da ostectomia 2,0\% $(0,4 \mathrm{ml})$.

Para o procedimento cirúrgico, os coelhos foram posicionados em decúbito dorsal, realizada antissepsia das regiões proximais das tíbias direitas com gluconato de clorexidine a $2 \%$, e proteção da área cirúrgica com panos de campos estéreis. Com o uso de um bisturi (cabo no 3 e lâmina nำ11), foi criada incisão cutânea, seguida de dissecção plano a plano do tecido subcutâneo e exposição do córtex da porção médio-proximal da tíbia direita. Ato contínuo, criou-se uma falha óssea com remoção de segmento cortical osteoperiosteal, com uso de broca trefina de $6 \mathrm{~mm}$ de diâmetro externo acoplado a um perfurador ortopédico.

As falhas ósseas das tíbias dos animais dos Grupos E1, E2, E3 e E4 foram preenchidas com o compósito autoclavado (Fig.2), aposição do tecido subcutâneo com fio absorvível sintético multifilamentar (poliglactina 910, 3-0), com padrão de sutura em zigue-zague e aproximação da incisão cutânea com fio não absorvível sintético monofilamentar (poliamida, 3-0), com padrão de sutura interrompida simples.

Cada animal recebeu cinco aplicações, a cada $24 \mathrm{~h}$, de enrofloxacina $(10 \mathrm{mg} / \mathrm{kg})$, por via subcutânea; três aplicações, a cada $24 \mathrm{~h}$, de meloxicam $(0,2 \mathrm{mg} / \mathrm{kg})$, por via subcutânea; seis aplicações, a cada $12 \mathrm{~h}$, de cloridrato de tramadol ( $4 \mathrm{mg} / \mathrm{kg}$ ), por via sub-

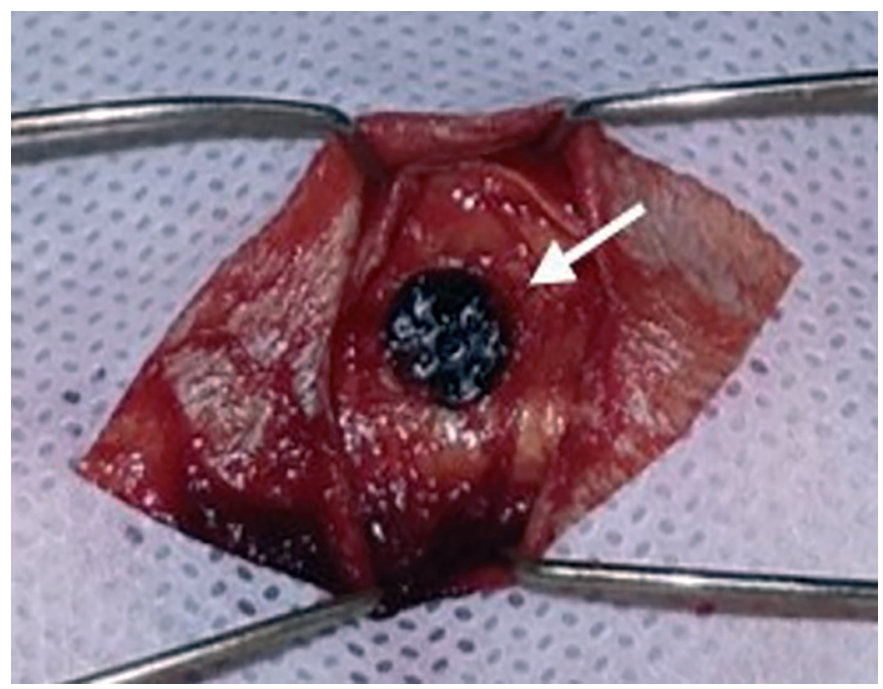

Fig.2. Falha óssea de tíbia de coelho preenchida com compósito de esferas de quitosana e polimetilmetacrilato (PMMA) (seta branca).

cutânea, e curativo local a cada $24 \mathrm{~h}$, com rifamicina, até a retirada dos pontos que ocorreu por volta do décimo dia.

Os animais foram alojados individualmente em gaiolas, alimentados com ração comercial para coelho e água ad libitum, e avaliados diariamente em relação ao apoio dos membros e aumento de volume da região cirúrgica.

As falhas ósseas preenchidas com compósitos foram avaliadas radiograficamente $(50 \mathrm{~mA}, 0,04 \mathrm{~s}$ e $40 \mathrm{KV})$, na posição mediolateral, no pós-operatório imediato, aos 30, 60 e 90 de pós-operatório.

Ao final de cada período de avaliação, os animais foram submetidos à eutanásia ativa, com uso de acepromazina $0,2 \%$ (1mg/ $\mathrm{kg}$ pela via subcutânea), tiopental sódico 2,5\% (30 mg/kg pela via endovenosa) e cloreto de potássio 19,1\% (pela via endovenosa), até a parada cardiorrespiratória. 0 acesso venoso foi pela veia auricular, através de cateter no 23 .

As regiões proximais mediais das tíbias direitas, que tiveram os compósitos implantados, foram macroscopicamente avaliadas antes e após a remoção dos tecidos moles adjacentes.

De cada tíbia operada foi realizada ostectomia de um segmento ósseo $(1,0 \mathrm{~cm}$ de comprimento por $1,0 \mathrm{~cm}$ de largura) envolvendo o compósito-leito receptor leito receptor e o compósito, com o uso de disco diamantado dupla-face acoplado em uma micro-retífica elétrica, em água corrente. Após remover o conteúdo celular medular em água corrente, as amostras foram fixadas em formol tamponado a $10 \%$, por 48 horas, desidratadas em temperatura ambiente e emblocadas em resina acrílica de polimetilmetacrilato, em forma de $13 \mathrm{~mm}$ de diâmetro por $3 \mathrm{~mm}$ de altura.

Duas mostras emblocadas de cada grupo experimental (E1, E2, E3 e E4) tiveram as irregularidades de suas faces externas, região periosteal, envolvendo o compósito-leito receptor, aplainadas/lixadas, com o uso de lixas d'agua (no 400 a 2000) acopladas à politriz/lixadeira metalográfica, em água corrente, até atingir uma superfície plana e regular. Ato contínio, as superfícies das amostras previamente preparadas foram polidas em pano de polimento $(20 \mathrm{~mm})$ acoplado à politriz, irrigado com solução de alumina $(0,3 \mu)$ (Volpon 1985, Mayer et al. 2013).

As amostras preparadas foram fixadas em porta amostra "stub" com fita adesiva dupla-face condutora de carbono e analisadas em microscópio eletrônico de varredura (MEV), sob tensão de aceleração de $15 \mathrm{Kv}$ e baixo vácuo (modelo TM3000, HITACHI - Japão), modo composicional, e as imagens capturadas pelo software anexado ao microscópio. 
De cada amostra foram obtidas quatro eletromicrografia com aumento de 50X, 100X, 500X e 1000X, envolvendo as interfaces do compósito-leito receptor e armazenadas no formato TIF para Windows.

\section{RESULTADOS E DISCUSSÃO}

Dos coelhos envolvidos no experimento, apenas um do grupo E2 veio a morte, no 19 dia, por causa não investigada, e sete apresentaram edema no local da feriada cirúrgica no 9o dia de pós-operatório, que se reduziu no $15^{\circ}$ dia.

No pós-operatório, não foi observado sinal de claudicação nos membros operados na ocasião dos exames físicos-ortopédicos diários, demonstrando que a ostectomia não comprometeu a estrutura da tíbia e que a analgesia utilizada foi adequada, que também foi observado na pesquisa realizada por Moreira et al. (2014).

A retirada dos pontos ocorreu por volta do $12^{\circ}$ dia e não foi observado deiscência de ferida e sinal que caracterizasse processo infeccioso, demonstrando que não só a técnica de esterilização, mas também o manejo das feridas, foram eficientes (Freitas et al. 2014).

0 polimetilmetacrilato é um biomaterial sintético biocompatível e biotolerável amplamente utilizado em procedimentos cirúrgicos ortopédicos para corrigir defeitos ósseos (Yacubian-Fernandes et al. 2004, Raposo-do-Amaral et al. 2010, Moreira et al. 2014), que pode ser utilizado a outros biomateriais, como a quitosana, objeto de estudo, para agregar propriedades individuais desejáveis e superiores quando comparado aos componentes isolados.

As avaliações radiográficas no pós-operatório imediato (D0) de tíbias direitas de coelhos, na projeção mediolate-

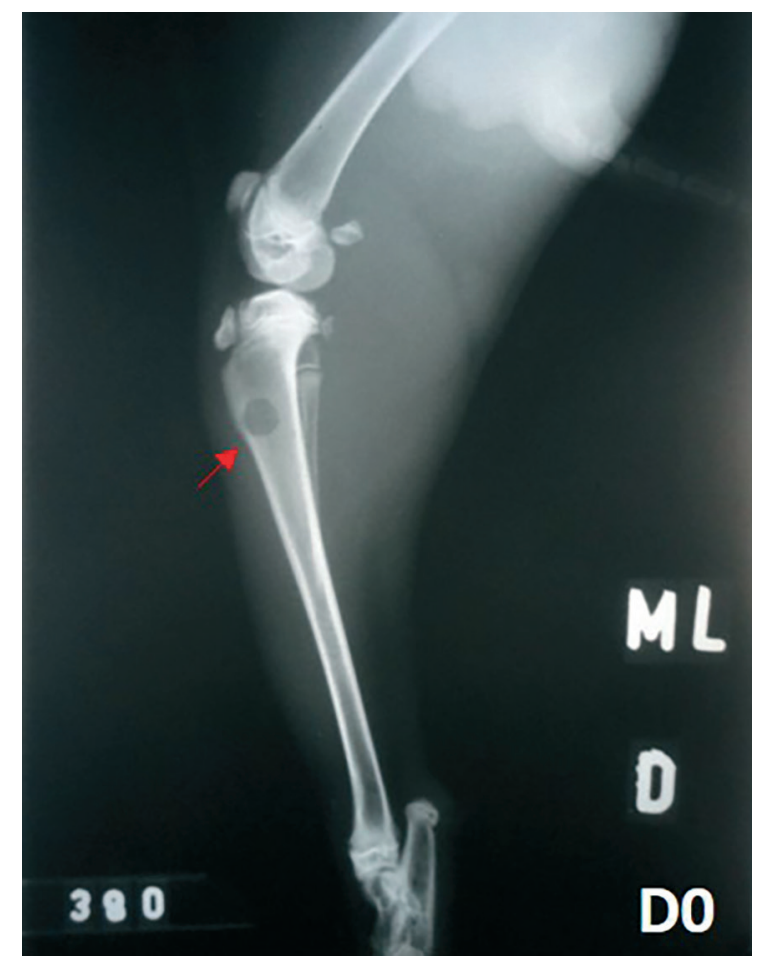

Fig.3. Imagem radiográfica, na projeção mediolateral, no pós-operatório imediato de tíbia direita de coelho. Observe área circular radioluscente do leito receptor, no qual foi implantado o compósito (seta vermelha). ral, apresentam área circular radioluscentes que compreende o leito receptor, no qual foi implantado o compósito (seta vermelha). Como estes são constituídos de polimetilmetacrilato e quitosana, que possuem baixas densidades, eles não são detectados através da técnica radiográfica, demonstrando área radioluscente (Fig.3).

No $30^{\circ}$ dia (E1), por meio de avaliação radiográfica, notou-se que os leitos receptores implantados das tíbias mantiveram aspectos circulares, demonstrando pouca diferença em relação às do pós-operatório imediato (Fig.4A). Já no 60ํ dia (E2), as imagens radiográficas das tíbias implantadas, apresentavam-se as bordas irregulares e com aumento de radiopacidade (Fig.4B), quando comparadas com as imagens das tíbias dos animais do grupo E1. Avaliações radiográficas, nos $90^{\circ}$ (E3) e $120^{\circ}$ (E4) dias, de todos os leitos receptores implantados, encontrava-se com radiopacidade aumentada, semelhante às do tecido ósseo adjacente (Fig.4C,D). Esse aumento progressivo de radiopacidade observado nos grupos experimentais (E1, E2, E3 e E4), demonstra que os leitos receptores foram, progressivamente, preenchidos com tecido ósseo (Spadeto Jr et al. 2011, Moreira et al. 2014).

Após eutanásia, com uso de lâmina de bisturi no 23, criou-se incisão cutânea longitudinal sobre a porção mé-

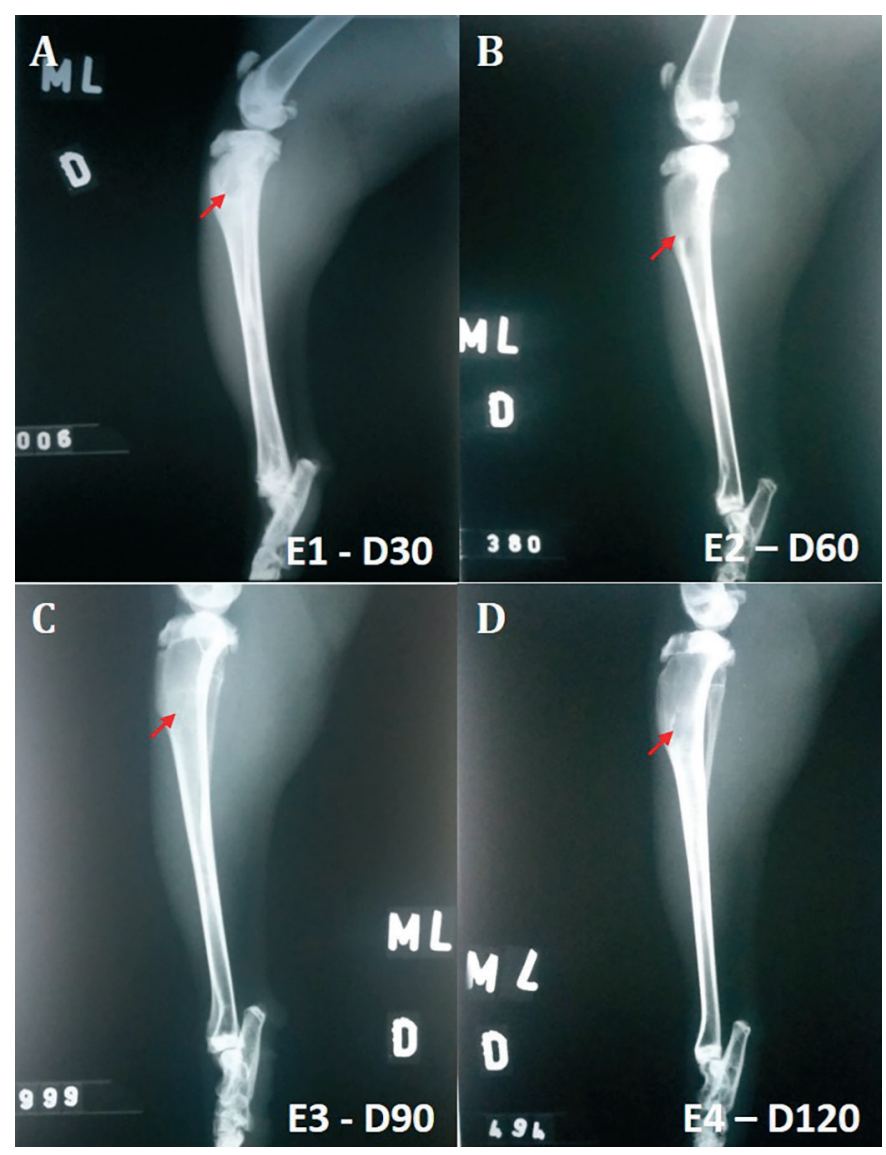

Fig.4. Imagem radiográfica, na projeção mediolateral, no pós-operatório imediato de tíbia direita de coelho dos grupos E1, E2, E3 e E4. (A - seta) Leito receptor circular com leve aumento de radiopacidade. (B,C,D - setas) Leitos receptores preenchido com tecido de radiopacidade semelhante a do tecido ósseo adjacente. 


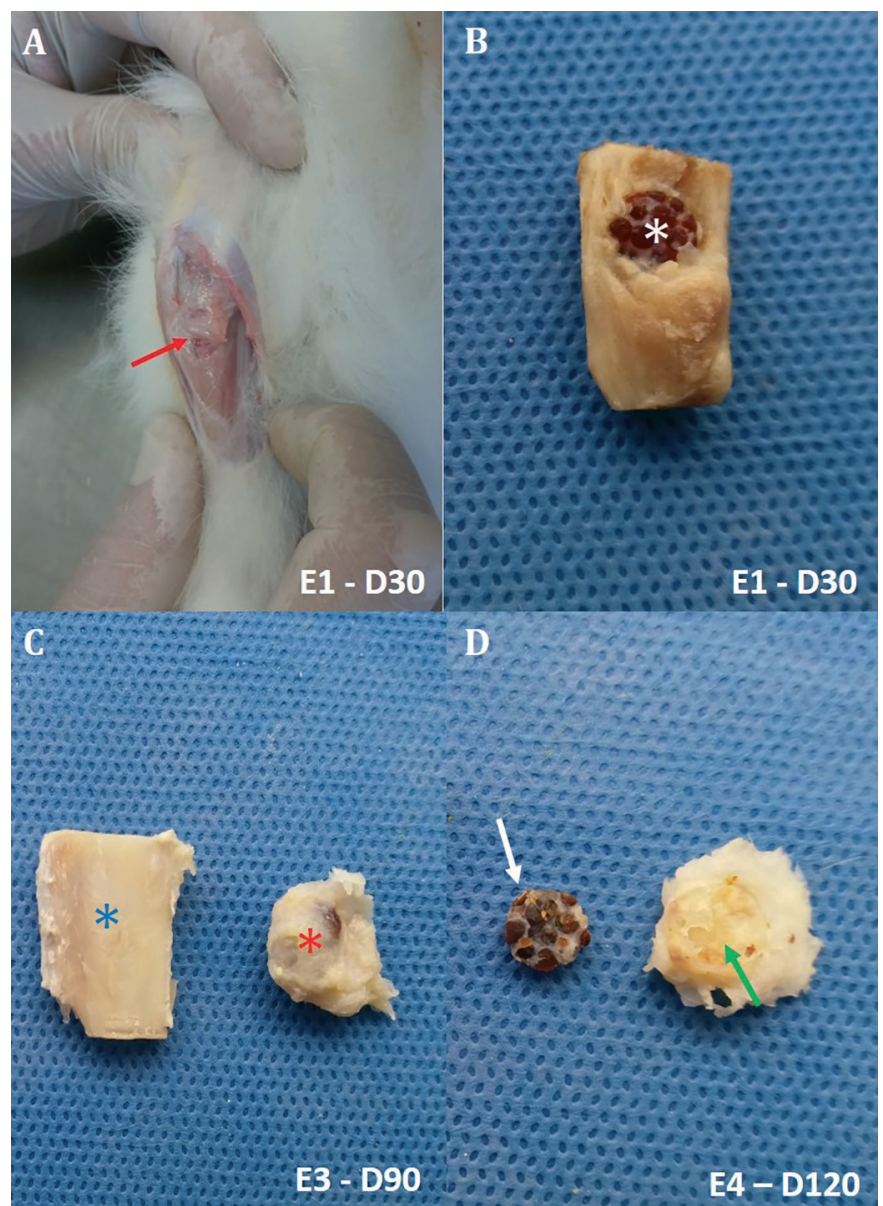

Fig.5. (A) Região metafisária de tíbias direita de coelho do grupo E1. (B) Compósito posicionado no leito receptor. (C) Região metafisária de tíbia direita de coelho do grupo E3: observe falha óssea preenchido (asterisco azul) e compósito encapsulado (asterisco vermelho). (D) Compósito (seta branca) removido de tecido subcutâneo, cápsula (seta verde), de coelho do grupo E4.

dio-proximal das tíbias direitas dos coelhos, com exposição da região do leito receptor e tecidos moles adjacentes. Após avaliação macroscópica, foi realizada coleta dos segmentos de tíbias envolvendo compósito-leito receptor dos animais dos grupos E1, E2, E3 e E4 (Fig.5A).

À avaliação macroscópica, no $30^{\circ}$ dia, observou-se que os compósitos implantados nas tíbias dos animais do Grupo E1 (1, 2 e 3) encontravam-se envolvidos por tecido conjuntivo (Fig.5A), sendo que dois permaneciam dentro do leito receptor (1 e 2) (Fig.5B) e um (3) fora e encapsulado, apresentando mobilidade à manipulação. Já aos $60^{\circ}$, $90^{\circ} \mathrm{e}$ $120^{\circ}$ dias, todos os compósitos implantados nas tíbias dos animais dos Grupos E2 (1, 2 e 3), E3 (1, 2 e 3) e E4 (1, 2 e 3) estavam deslocados de seus leitos receptores, encapsulados (Fig.5C - asterisco vermelho) e, também, com presença de mobilidade ao toque digital.

O leito receptor da tíbia do coelho 3 do Grupo E1 estava, ao exame macroscópico, preenchido com tecido com características diferentes à do tecido ósseo adjacente. Por outro lado, os leitos receptores das tíbias dos animais dos Grupos E2, E3 e E4, encontravam-se preenchidos com tecido semelhante ao tecido ósseo adjacente (Fig.5C - asterisco azul).
Devido às suas propriedades de biocompatibilidade, biodegradabilidade e bioatividade, atualmente o polímero de quitosana vem sendo pesquisado e aplicado como substituto ósseo, pois é um biomaterial biodegradável que vai sendo substituída por tecido ósseo (Muzzarelli \& Muzzarelli 2002, Spin-Neto et al. 2008, Pires et al. 2015), evento que também foi observado em pesquisa envolvendo lesões periodontais com perdas ósseas (Akncbay et al. 2007). Neste estudo, as esferas de quitosana presentes nos compósitos dos grupos experimentais, que permaneceram no leito receptor do grupo E1 (1 e 2) (Fig. 5B), e as dos compósitos que foram encapsulados no tecido subcutâneo dos grupos E1 (3), E2, E3 e E4 (Fig.5C - asterisco vermelho), não sofreram processo de degradação (Fig.5D - seta branca). Além disso, também não foi observada deposição de tecido ósseo nas esferas de quitosana dos compósitos dos animais do grupo E1 (Fig.7), demonstrando que as propriedades inerentes a esse biomaterial natura, ora citadas nas literaturas, não foram observadas neste estudo.

A quitosana, para que possa ser utilizada como biomaterial na reparação de falha óssea, tem que passar por processo de esterilização que pode ser por meio de exposição ao calor seco, vapor pressurizado, óxido de etileno e radiação ionizante gama. Quando exposta à temperatura superior a $120^{\circ} \mathrm{C}$, ela sofre alterações em seu grau de solubilidade, aparência e estrutura física, que provavelmente poderá alterar suas propriedades biológicas (Lim et al 1998, Spin-Neto et al. 2008). Para uso, o compósito constituído de esferas de quitosana e PMMA foi esterilizado em autoclave a $121^{\circ} \mathrm{C}$, por 15 minutos. Após esse período de exposição ao calor úmido, observou-se mudança de coloração das esferas de quitosana, passando de marrom claro ao escuro, e que as fissuras presentes (Fig.6A) desapareceram, tornado o biomaterial mais homogêneo, após a esterilização (Fig.6B).

Quanto a osteointegração, atualmente, não possui um consenso entre os estudiosos que pesquisam sobre a biologia do tecido óssea. Por isso, pesquisas relacionadas às respostas biológicas local, a biomecânica e os biomateriais que influenciam a osteointegração de implantes ao leito receptor, são imperativos e estão sendo realizados (Legeros \& Craig 1993, Moreira et al. 2014, Freitas et al. 2014). Os biomaterias funcionais podem ter contato direto, osteointegração, ou indireto, fibrointegração, com o leito receptor;
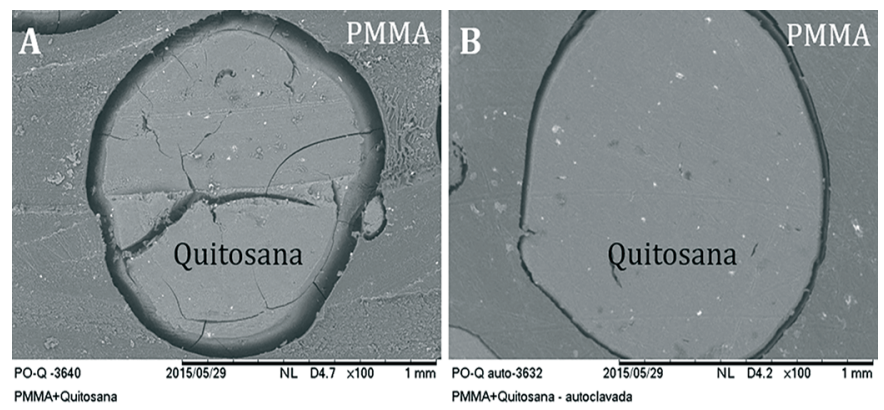

Fig.6. Eletromicrografias obtidas por meio de MEV do compósito constituído de quitosana e polimetilmetacrilato (PMMA) antes e após a esterilização. (A) Fissuras na superfície da esfera de quitosana. (B) Superfície uniforme da esfera de quitosana após esterilização por meio de autoclave. 

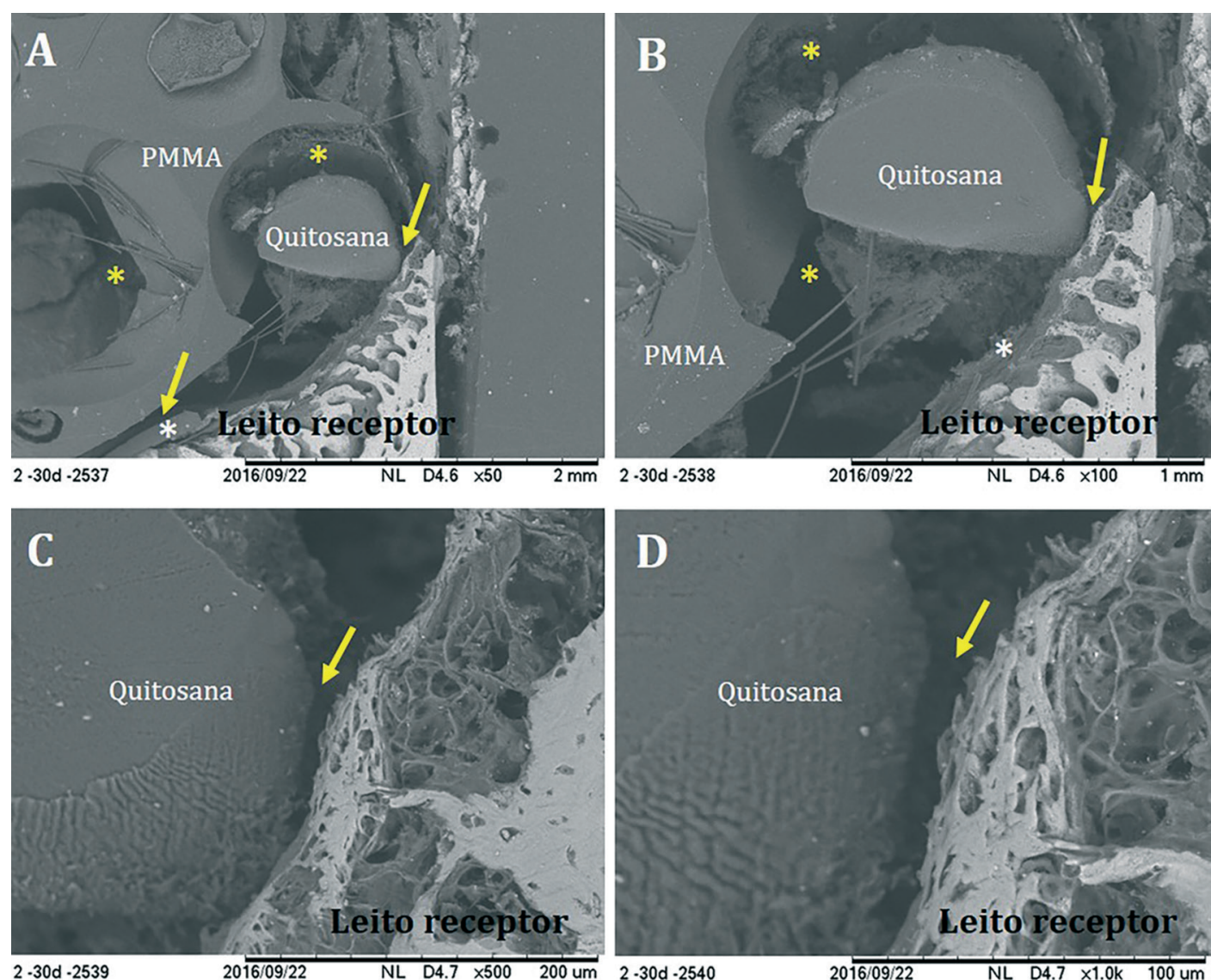

Fig.7. Eletromicrografias obtidas por meio de MEV do compósito constituído de quitosana e polimetilmetacrilato (PMMA) no leito receptor de tíbia direita de coelho do grupo E1. Observe: leito receptor, esfera de quitosana, PMMA, interface entre o compósito e leito receptor (seta amarela), tecido não mineralizado: tecido fibroso com feixes de fibras (asterisco branco) e espaço entre PMMA e quitosana (asterisco amarelo). (A) 50x, (B) 100x, (C) 500x, (D) 1000x.

entretanto a falha e a perda desses tem sido atribuída à formação de tecido fibroso, ou seja, a osteointegração indireta, que pode ser analisada pela técnica de MEV (Legeros \& Craig 1993, Kang et al. 2015), e que também foi utilizada neste estudo. Por meio da MEV, observou osteointegração indireta entre o leito receptor e o PMMA do compósito de todas as tíbias implantadas e não notou osteointegração direta das esferas de quitosana presentes nos compósitos com o leito receptor dos animais do grupo E1 (1 e 2) (Fig.7).

Por meio de técnica de microscopia eletrônica de varredura (MEV), a interface entre biomaterial e leito receptor teve suas estruturas analisadas em alta resolução, uma vez que análises histológicas e histomorfométricas não são métodos apropriados para observar tecidos com diferentes propriedades mecânicas e densidades, já que são fatores fundamentais para a compreensão da biologia óssea local (Saboia et al. 2000, Huja \& Roberts, 2004, Mayer et al. 2013, Costa et al. 2015). Com isso, estabeleceu não só o limite entre o contato físico do compósito com o leito receptor, mas também análise da superfície de seus componentes, demonstrando que a MEV é um método valioso para estudo das estruturas presentes na interface entre o compósito e o leito receptor de tíbias de coelhos. Dos grupos experimentais em estudo, apenas os compósitos das tíbias dos coelhos (1 e 2), do grupo E1, permaneceram implantados em seus leitos receptores (Fig.7).
Observou-se, também, que o tecido ósseo do leito receptor (cinza claro) e os constituintes dos compósitos, ou seja, a quitosana (cinca escuro) e o PMMA (cinza escuro) encontravam-se preservados. Além disso, também se notou presença de fendas entre o PMMA e a quitosana, devido desidratação na ocasião do processamento da amostra, e presença de tecido não mineralizado, ou seja, tecido fibroso adjacente à superfície do implante (cinza escuro), com estruturas distintas às do tecido ósseo presente no leito receptor (Fig.7).

\section{CONCLUSÕES}

Dos compósitos implantados nas tíbias de coelhos, apenas dois permaneceram em seus leitos receptores, enquanto que os demais se encontravam encapsulados no tecido subcutâneo.

As esferas de quitosana, presentes nas superfícies dos biomateriais implantados, que mantiveram contato direto com o leito receptor de tíbias de coelhos apresentavam-se preservadas e não integraram ao tecido ósseo.

Para melhor compreensão do comportamento da quitosana como substituto ósseo, novas pesquisas serão necessárias.

Agradecimentos.- À Fundação de Apoio à Pesquisa do Estado de São Paulo-FAPESP, pelo apoio à Pesquisa de Iniciação Científica. 


\section{REFERÊNCIAS}

Akamoto T. \& Trento C.L. 2002. Implante homógeno de matriz dentinária desmineralizada conservada em glicerina a $98 \%$ em alvéolo dental: estudo microscópico em rato. Revta Ciênc. Odont. 5:33-43.

Akncbay H., Senel S. \& Ay Z.Y. 2007. Application of chitosan gel in the treatment of chronic periodontitis. J. Biomed. Mater. Res. B, Appl. Biomater. 80:290-296.

Alexander J.W. 1987. Bone grafting. Vet. Clin. N. Am., Small Anim. Pract. 17:811-819.

Alievi M.M., Schossler J.E.W., Guimarães L.D., Oliveira A.N.C., Traeslel C.K. \& Ferreira P. 2007. Implante ósseo cortical alógeno conservado em mel na reconstrução de falha óssea diafisária em fêmur de cães: avaliação clínica e radiográfica. Ciência Rural 37:450-457.

Alves E.G.L., Rezende C.M.F., Oliveira H.P., Borges N.F., Mantovani P.F. \& Rosado I.R. 2010. Emprego experimental da placa de compósito poli-hidroxibutirado/hidroxiapatita na fixação femoral em gatos. Arq. Bras. Med. Vet. Zootec. 62:1128-1134.

Bauer T.W. \& Muschler G.F. 2000. Bone Graft Materials. Clin. Orthop. 37:10-27.

Braz F., Rahal S.C., Rocha N.S., Taga E. \& Biasi F. 2003. Emprego de matriz óssea orgânica bovina e hidroxiapatita no reparo de defeito induzido em crânio de ratos. Acta Cir. Bras. 18:01-12.

Burger C.P., Moraes P.C., Maniscalco C.L., Borges P.A., Batista P.A.C.S., Canola J.C., Meirelles A.E.W.B., Sabino M.G. \& Rossetto H. 2013. Cimento de aluminato de cálcio: uso em defeitos ósseos induzidos em fêmur de coelhos. Arq. Bras. Med. Vet. Zootec. 65:757-762.

Carneiro E., Garcia R.B., Oliveira R.C., Moraes F.G., Menezes R., Letra A., Canova G.C., Cestari T.M. \& Granjeiro J.M. 2005. Microscopic and radiographic analysis of the effect of particle size of demineralized bovine cancellous bone matrix on the repair of bone defects in femurs of rabbits. J. Appl. Oral Sci. 13:157-162.

Chen X., Xia W.S. \& Yu X.B. 2005. Purification and characterization of two types of chitosanase from Aspergillus sp CJ22-326. Food Res. Inter. 38:315-322.

Costa B.D., Camargo N.H., Oleskovicz N., Gava A., Dallabrida A.L., Regalin D., Lima M.P.A. \& Moraes A.N. 2015. Neoformação óssea e osteointegração de biomateriais micro e nanoestruturados em ovinos. Pesq. Vet. Bras. 35:177-187.

Dasso G., Fernandez M.S. \& Arias J.L. 1998. Reparacion óssea mediante aloimplantes sometidos a diferentes métodos de conservación em conejos. Arch. Med. Vet. 30:57-66

Fernandes M.B., Guimarães J.A., Casado P.L., Cavalcanti A.S., Gonçalves N.N., Ambrósio C.E., Rodrigues F., Pinto A.C., Miglino M.A. \& Duarte M.E. 2014. The effect of bone allografts combined with bone marrow stromal cells on the healing of segmental bone defects in a sheep model. BMC Vet. Res. 10(1):36. doi: 10.1186/1746-6148-10-36.

Freitas S.H., Dória R.G.D., Mendonça F.S., Evêncio Neto J. \& Camargo L.M. 2008. Aspecto radiológico de heteroenxerto ósseo cortical fragmentado na reparação de falhas ósseas em coelhos. Revta Bras. Ciênc. Vet. 15:107-110.

Freitas S.H., Dória R.G.S., Mendonça F.S., Santos M.D., Moreira R., Simões R.S., Camargo L.M., Marques A.T.C. \& Simões M.J. 2012. Tomografia computadorizada da matriz óssea mineralizada heteróloga fragmentada e metilmetacrilato na reparação de falhas ósseas. Arq. Bras. Med. Vet. Zootec. 64:1547-1554.

Freitas S.H., Dória R.G.D., Mendonça F.S., Camargo L.M., Presser C.I., Santos M.D., Shimano A.C. \& Ambrósio C.E. 2013a. Avaliação morfológica e por imagem radiográfica da matriz óssea mineralizada heteróloga fragmentada e metilmetacrilato preservados em glicerina para reparação de falhas ósseas em tíbias de coelhos. Pesq. Vet. Bras. 33:765-770.

Freitas S.H., Dória R.G.S., Minto B.W., Nardi A.B., Melo M.M., Camargo L.M., Santos M.D., Shimano A.C. \& Ambrósio C.E. 2013b. Haste intramedular modificada no tratamento de fratura diafisária de fêmur em cão - relato de caso. Revta Bras. Med. Vet. 35:323-328.

Freitas S.H., Dória R.G.S., Mendonça F.S., Santos M.D., Engrácia Filho J.R., Vidane A.S., Marques A.T.C. \& Ambrósio C.E. 2014. Tomographic imaging of fragmented cortical bone heteroimplant and methylmethacrylate in segmental bone defect of rabbit tibia. Acta Cir. Bras. 29:794-800.

Friedlaender G.E. 1982. Current concepts review: bone banking. J. Bone Joint Surg. 64:307-311.

Gutierres M., Lopes M.A., Hussain N.S., Cabral A.T., Almeida L. \& Santos J.D. 2006. Substitutos ósseos: revisão. Arq. Med. 19:153-162.

Gartner L.P. \& Hiatt J.L. 1999. Tratado de Histologia em Cores. Guanabara Koogan, Rio de Janeiro. 426p.

Gerentes P., Vachoud L., Doury J. \& Domard A. 2002. Study of a chitin-based gel as injectable material in periodontal surgery. Biomaterials 23:1295-1302.

Huja S.S. \& Roberts W.E. 2004. Mechanics of osseointegration: characterization of supporting bone with indentation testing and backscattered imaging. Sem. Orthodont. 10:162-173.

Kang C.-G., Park Y.-B., Choi H., Oh S., Lee K.-W., Choi S.-H. \& Shim J.-S. 2015. Osseointegration of implants surface-treated with various diameters of $\mathrm{TiO}_{2}$ nanotubes in rabbit. J. Nanomaterials 2015:11. doi. org/10.1155/2015/634650.

Kawano C.T., Romano Neto O. \& Monteiro A.C. 1998. Classificação dos defeitos ósseos e métodos de correção nas artroplastias primárias de joelho. Revta Bras. Ortop. 33:287-290.

Khor E. \& Lim L.Y. 2003. Implantable applications of chitin and chitosan. Biomaterials 24:2339-49.

Lane J.M. \& Sandhu H.S. 1987. Current approaches to experimental bone grafting. Orthoped. Clin. North. Am. 18:213-225.

Legeros R.Z. \& Craig R.G. 1993. Strategies to affect bone remodeling: osseointegration. J. Bone Min. Res. 8:583-596.

Lim L.Y., Khor E. \& Koo O. 1998. Gamma irradiation of chitosan. J. Biomed. Mater. Res. 43:282-290.

Mayer L., Oliveira M.G., Massotti F.P., Gomes F.V., Guyoti V., Melo E.G., Rezende C.M.F., Borges A.P.B. \& Nobrega Neto P.I. 1998. Aloenxerto ósseo cortical: avaliação do seu emprego em tíbia de cão. Arq. Bras. Med. Vet. Zootec. 50: 385-394.

Mayer L., Oliveira M.G., Massotti F.P., Gomes F.V., Guyoti V., González F.H.D. \& Weber J.B.B. 2013. Metodologia para avaliação do efeito sistêmico e local da LLLT na osseointegração de implantes dentários em mandíbula de coelhos: nota prévia. RFO 18:235-245.

Melo E.G., Rezende C.M.F., Borges A.P.B. \& Nobrega Neto P.I. 1998. Aloenxerto ósseo cortical: avaliação do seu emprego em tíbia de cão. Arq. Bras. Med. Vet. Zootec. 50:385-394.

Mendes A.A., Oliveira P.C., Castro H.F. \& Giordano R.L.C. 2011. Aplicação de quitosana como suporte para a imobilização de enzimas de interesse industrial. Quím. Nova 34:831-840.

Milori F.P., Quitzan J., Souza R.S., Cirio S.M., Dornbusch P.T. \& Prado A.M.R.P. 2013. Placas ósseas confeccionadas a partir de diáfise cortical equina na osteossíntese femoral em coelhos. Pesq. Vet. Bras. 33:1201-1207.

Moraes P.C., Padilha Filho J.G., Canola J.C., Santos L.A., Macoris D.G., Alessi A.C., Castro M.B. \& Dória Neto F. 2004. A biocompatibilidade do cimento de fosfato de cálcio implantado no rádio de coelhos. Acta Cir. Bras. 19:351-359.

Moreira R., Dória R.G.S., Camargo L.M., Santos M.D., Minto B.W., De Nardi A.B., Ambrósio C.E. \& Freitas S.H. 2014. Aspecto radiológico e macroscópico de matriz óssea mineralizada heteróloga e polimetilmetacrilato autoclavado em falha óssea de tíbia de coelhos. Pesq. Vet. Bras. 34:173-178.

Muzzarelli C. \& Muzzarelli R.A. 2002. Natural and artificial chitosan-inorganic composites. J. Inorg. Biochem. 92:89-94.

Pires A.L.R., Bierhalz A.C.K. \& Moraes A.M. 2015. Biomateriais: tipos, aplicações e mercado. Quím. Nova 38:957-971.

Rahal S.C., Bergamo F.M.M. \& Ishiy H.M. 2000. Prótese intra-ocular de resina acrílica em cães e gatos. Arq. Bras. Med. Vet. Zootec. 52:319-324.

Ranzani J.J.T., Sampaio G.R., Franco M. \& Castro G.B. 1996. Aplicação de membrana biológica heteróloga conservada em glicerina, na reparação de lesão em coelhos. Vet. Zootec. 8:35-45.

Raposo-do-Amaral C.A.A., Raposo-do-Amaral C.E., Roland F.G., Silva J.V.L., Paschoal G.H.L. \& Silva A.M. 2010. Implantes pré-fabricados customizados nas grandes perdas ósseas do esqueleto craniofacial. Revta Bras. Cir. Craniomaxilofacial 3:175-179. 
Rezende C.M.F, Borges A.P.B., Bernis W.O., Melo E.G. \& Nobrega Neto P.I. 1998. Aspecto clínico-cirúrgico e radiográficos da hidroxiapatita sintética na diáfise proximal da tíbia de cães. Arq. Bras. Med. Vet. Zootec. 50:537-545.

Rocha F.S., Ramos L.M.A., Batista J.D., Zanetta-Barbosa D. \& Dechichi P. 2011. Organic bovine graft associated with prp in rabbit's calvaria. Int. Arch. Otor. 15:208-213.

Saboia V.P.A., Saito S.K. \& Pimenta L.A.F. 2000. Aspectos micromorfológicos da interface adesiva em função da variação no preparo do espécime. Pesq. Odont. Bras. 14:340-344.

Sinibaldi K. 1989. Evaluation of full cortical allografts in 25 dogs. J. Am. Vet. Med. Assoc. 194:1570-1577.

Spin-Neto R., Pavone C., Freitas R.M., Marcantonio R.A.C. \& Marcantonio-Júnior E. 2008. Biomateriais à base de quitosana com aplicação médica e odontológica: revisão de literatura. Revta Odont. Unesp 37:155-161.
Tadjoedin E.S., Tadjoedin E.S., De Lange G.L., Bronckers A.L.J.J., Lyaruu D.M. \& Burge E.H. 2003. Deproteinized cancellous bovine bone (Bio-Osso) as bone substitute for sinus floor elevation: a retrospective, histomorphometrical study of five cases. J. Clin. Periodontol. 30:261-270.

Timm L.L. 2005. Técnicas rotineiras de preparação e análise de lâminas histológicas. Caderno La Salle XI, Canoas. 2:231-239.

Volpon J.B. 1985. A marcação do osso com substâncias fluorescentes. Revta Bras. Ortop. 20:207-210.

Weinfeld I., Magalhães L.V. \& Vila N. 1999. Estudo histológico de um novo material (biobone) indicado para reparação óssea. Revta Paul. Odont. 21:9-10.

Yacubian-Fernandes A., Laronga P.R., Coelho R.A., Ducati L.G. \& Silva M.V. 2004. Prototipagem como forma alternativa para realização de cranioplastia com metilmetacrilato: nota técnica. Arq. Neuropatol. Psiquiatr. 62:865-868. 